Article

\title{
Development of an Anti-Idiotypic VHH Antibody and Toxin-Free Enzyme Immunoassay for Ochratoxin A in Cereals
}

\author{
Caixia Zhang ${ }^{1,2,3,+}$, Qi Zhang ${ }^{1,2,4,+}$, Xiaoqian Tang ${ }^{1,2,4}$, Wen Zhang ${ }^{1,2}$ and Peiwu Li ${ }^{1,2,3,4, *}$ \\ 1 School of Life Sciences, Hubei University, Wuhan 430062, China; zcx1778253705@163.com (C.Z.); \\ zhangqi01@caas.cn (Q.Z.); wtxqtutu@163.com (X.T.); zhangwen@oilcrop.cn (W.Z.) \\ 2 Oil Crops Research Institute of the Chinese Academy of Agricultural Sciences, Wuhan 430062, China \\ 3 Key Laboratory of Biology and Genetic Improvement of Oil Crops, Ministry of Agriculture, \\ Wuhan 430062, China \\ 4 Key Laboratory of Detection for Mycotoxins, Ministry of Agriculture, Wuhan 430062, China \\ * Correspondence: peiwuli@oilcrops.cn \\ + Both C. Zhang and Q. Zhang rank as the first authors.
}

Received: 22 April 2019; Accepted: 12 May 2019; Published: 20 May 2019

\begin{abstract}
Enzyme-linked immunosorbent assay (ELISA) test kits have been widely used for the determination of mycotoxins in agricultural products and foods, however, this test uses toxin standards with high toxicity and carcinogenicity that seriously threaten human health. In this work, the anti-idiotypic nanobody VHH 2-24 was first developed and then, using it as a surrogate standard, a toxin-free enzyme immunoassay for ochratoxin A (OTA) was established. The $\mathrm{IC}_{50}$ value of the VHH 2-24 surrogate standard-based ELISA was $0.097 \mu \mathrm{g} / \mathrm{mL}$, with a linear range of $0.027-0.653 \mu \mathrm{g} / \mathrm{mL}$. The average recoveries were tested by spike-and-recovery experiments, and ranged from $81.8 \%$ to $105.0 \%$. The accuracy of the developed ELISA for detecting OTA was further verified by using the high performance liquid chromatography (HPLC) method, and an excellent correlation was observed. In summary, the toxin-free ELISA established in this study proves the latent use of the anti-idiotypic $\mathrm{VHH}$ as a surrogate calibrator for other mycotoxins and highly toxic small molecule analysis to improve assay properties for highly sensitive analyte determination in agricultural products.
\end{abstract}

Keywords: anti-idiotypic nanobody; surrogate; Ochratoxin A; enzyme-linked immunosorbent assay

Key Contribution: The innovation of this study was the development of a toxin-free ELISA method using the ochratoxin A anti-idiotype nanobody as a substitute for the ochratoxin A standard, which reduces the harm of the toxin standard to the operator during the experiment, and provides a new method for the green immune analysis of mycotoxins.

\section{Introduction}

Ochratoxin A (OTA) is a secondary metabolite produced by the genus Aspergillus and Penicillium, especially A. ochraceus and P. verrucosum [1,2]. OTA mainly contaminates cereals, vegetables, coffee beans, fruits, cocoa and their derivatives such as bread, coffee and wine [3,4]. In addition, many studies have shown that OTA has a variety of toxic effects, including nephrotoxicity, hepatotoxicity, immunosuppression, carcinogenicity and teratogenicity [5-7], which has potential harm to animal and human [8]. In humans, the International Agency for Research on Cancer (IARC) has categorized ochratoxin A as a possible carcinogen (group 2B) [9]. Due to its widespread presence and chemical stability in food $[10,11]$, European countries have established strict regulatory limits for OTA in order 
to reduce public health risks [12]. In addition, there is an urgent need to establish low-cost, rapid, and highly sensitive methods to detect the presence of OTA in food to reduce its harm.

To date, a variety of analytical methods have been developed for the determination of OTA, including the thin-layer chromatographic (TLC) method, high-performance liquid chromatography, immunoassay, and electrochemical sensor methods [13-16]. Instrumental analysis methods are precise and sensitive; nevertheless, those methods are time-consuming and require complex sample pre-processing and expensive equipment. Alternatively, immunoassays based on the specific binding of the antigens and antibodies have the advantages of rapid sample preparation, selectivity, high sensitivity and cost effectiveness $[17,18]$. This means they are suitable for rapid screening of numerous samples in food safety testing. OTA is a small molecule compound; hence it is necessary to use a competitive immunoassay format to detect it [19]. However, in the establishment and application of immunoassay methods, the use of a large number of coating antigens synthesized by organic solvents and OTA standards seriously threaten the health of operators [20]. In addition, the waste liquid generated during the experiment may also cause secondary pollution of the surrounding environment. Therefore, we urgently need to develop a toxic-free immunoassay for detecting OTA.

In recent years, numerous studies have reported the superiority of developing toxin substitutes for immunoassays, mainly involving aflatoxins, deoxynivalenol, ochratoxin A, fumonisins, zearalenone and citrinin [21-26]. These alternatives can be obtained by the preparation of anti-idiotypic antibodies. In 1974, Jerne [27] first proposed the "network theory of the immune system", the core of which is the idiotype (Id) of antibodies that can induce the body to produce the anti-idiotypic (Anti-id or AId) antibodies. Anti-id antibodies, which are capable of specifically binding to the antigen-binding region of the antibody, form a relationship of "internal images" with the antigen, mimic the three-dimensional structure of the antigen, and thus act as a substitute for the antigen molecule [28,29]. According to the literature, monoclonal and polyclonal anti-id antibody technologies have been widely applied in vaccine development [30], disease treatment [31] and small molecule detection [32]. The anti-id polyclonal antibodies can be easily obtained in a short period of time at a low production cost; however, the single yield of antibodies is limited and there is variability in the antibodies from different animals. Although the monoclonal antibody can produce a stable single anti-id antibody, it has a longer production cycle and is an expensive process. Modern genetic engineering technology has provided new tools for the development of anti-id antibodies, such as fragment antigen binding (Fab) [33] and single chain variable fragments (scFv) [34]. Nevertheless, the shortcomings of Fab and scFv-low solubility and stability - prevent their wide application. In 1993, scientists discovered that there is a type of antibody that naturally lacks a light chain in the camelids [35] and sharks [36], which is called a heavy chain antibody. A single-domain heavy chain antibody containing only the heavy chain variable region can be produced by cloning and recombinant expression of the variable region of the heavy chain antibody. The Belgian company, Ablynx calls it a nanobody or VHH because its molecular weight is only about 17KD [37]. Compared with traditional recombinant antibodies, nanobodies have better solubility, high thermal stability and high tolerance to organic solvents [38]. In view of these advantages, $\mathrm{VHH}$ antibodies are more suitable for the development of alternative reagents for immunoassay. The anti-id nanobody is used as a surrogate for antigens and standards have been applied to the toxic-free green immunoassays for aflatoxins [21,39], further prompting us to study its use as an alternative to other mycotoxins. However, there are no reports on a toxin-free competitive ELISA for analyzing OTA by using anti-id VHH antibody as a surrogate standard.

In this study, we report the specificity and thermal stability of the anti-id nanobody VHH 2-24 developed in our experiment. The obtained VHH 2-24 was used as the surrogate standard to develop a toxic-free indirect competitive enzyme-linked immunosorbent assay for the detection of OTA in agricultural products. 


\section{Results and Discussion}

\subsection{Expression and Purification of the Anti-Id Nanobody}

TOP10F' is a non-suppressor cell that permits the expression of dissolvable VHH without the pIII protein. For expression, the phagemid containing the $\mathrm{VHH}$ gene was transformed into E. coli Top $10 \mathrm{~F}^{\prime}$, and the E.coli ER2738 periplasmic protein was extracted with xTractor buffer. The VHH 2-24 containing $6 \times$ His tag was purified on the Ni-NTA resin column. Then, the purified VHH 2-24 was characterized by a $12 \%$ SDS-PAGE gel. As shown in Figure 1, the size of the obtained VHH 2-24 is about $15 \mathrm{kDa}$, which is in accordance with the results computed by the protein information resource. There is only one band of target protein in the figure, which proves that the purification effect of $\mathrm{VHH}$ is good. We measured the concentration of the purified VHH 2-24 by the Bradford method and the result is $211.2 \mu \mathrm{g} / \mathrm{mL}$.

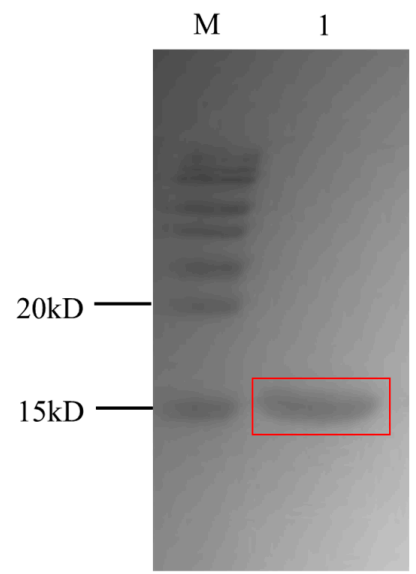

Figure 1. SDS-PAGE analysis of the purified VHH2-24 nanobody on $12 \%$ gel.

\subsection{Specificity of the Anti-Id Nanobody}

In our previous work, we demonstrated that the nanobody VHH 2-24 could be used as a coating antigen, which was shown to specifically bind to the anti-OTA mAb 1H2 (Figure 2), thus, we inferred that the $\mathrm{VHH}$ might specifically recognize the antigen binding site of the antibody. In order to prove this, we conducted a verification test. In this study, the specificity of the anti-id nanobody VHH 2-24 was determined by competitive ELISA with three mAbs: anti-AFB1 mAb, anti-DON mAb and anti-ZEN mAb. No conspicuous inhibition was observed when various concentrations of $\mathrm{VHH} 2-24$ were mixed with three mAbs; however, there was a significant inhibition of the binding between OTA and anti-OTA mAb 1H2. Therefore, these results showed that VHH 2-24 could be highly selective and could specifically bind with the variable region of the $\mathrm{mAb} 1 \mathrm{H} 2$.

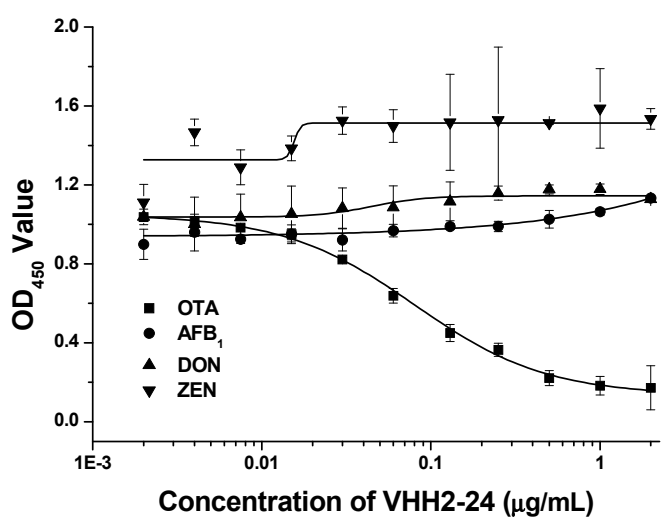

Figure 2. Specificity of VHH 2-24 towards anti-OTA, anti-AFB1, anti-DON and anti-ZEA monoclonal antibodies. 


\subsection{Thermal Stability of the VHH Surrogate Calibrator}

The thermal stability of the VHH antibody has played an important role in improving product stability and service life when VHH is used as an immunoassay reagent. First, we performed the thermal stability test on $\mathrm{VHH} 2-24$ at different temperatures to investigate this issue. The $\mathrm{VHH} 2-24$ solution diluted to a working concentration with PBS buffer was heated for $5 \mathrm{~min}$ at $20^{\circ} \mathrm{C}, 37^{\circ} \mathrm{C}, 50{ }^{\circ} \mathrm{C}$, $60{ }^{\circ} \mathrm{C}, 70^{\circ} \mathrm{C}, 80^{\circ} \mathrm{C}$ and $90^{\circ} \mathrm{C}$, respectively. After cooling to room temperature, the binding ability of the treated $\mathrm{VHH} 2-24$ with the monoclonal antibody $1 \mathrm{H} 2$ was tested by indirect non-competitive ELISA. As shown in Figure 3(a), we observed that as the temperature increases, the mAb $1 \mathrm{H} 2$ reactivity with OTA-BSA gradually decreases while the binding capacity of the VHH 2-24 hardly changes and VHH can still bind to the antibody at a temperature of $90^{\circ} \mathrm{C}$.

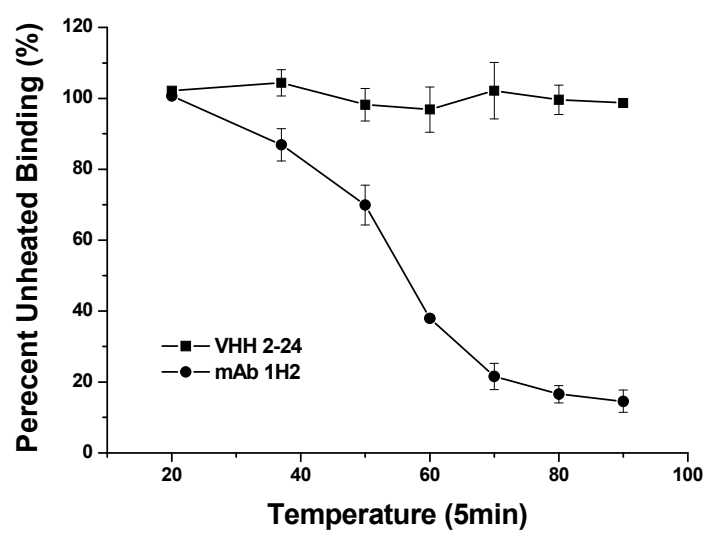

(a)

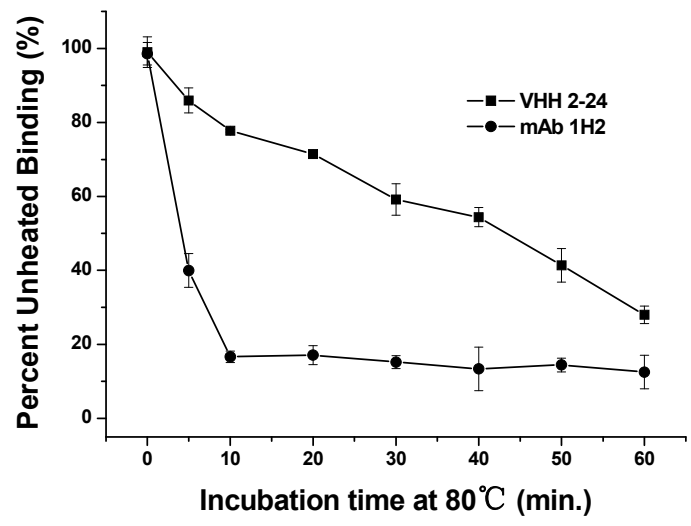

(b)

Figure 3. (a) Inhibition curves using VHH 2-24 as a standard surrogate after treatment under different temperatures; (b) Thermal stability of VHH 2-24 and monoclonal antibody $1 \mathrm{H} 2$.

To further verify this, the thermostability of VHH 2-24 was also studied by comparison with the monoclonal antibody $1 \mathrm{H} 2$ at various incubation times. VHH 2-24 and the monoclonal antibody $1 \mathrm{H} 2$ were incubated to $80^{\circ} \mathrm{C}$ for different times $(0,5,10,20,30,40,50,60 \mathrm{~min})$. Each of the samples was re-equilibrated to RT, followed by assaying for their binding activity. From Figure 3b, it can be seen that the monoclonal antibody $1 \mathrm{H} 2$ immediately lost its binding ability after incubation at $80^{\circ} \mathrm{C}$ for $10 \mathrm{~min}$. However, VHH 2-24 retained about $50 \%$ of its binding capacity after heating for $40 \mathrm{~min}$ at $80^{\circ} \mathrm{C}$. Consequently, VHH 2-24 has better thermostability than conventional antibodies and is more suitable for the development of alternative reagents for immunoassays. This result was expected because VHH can form an additional disulfide bond between CDR3 and CDR1 or FR2 in addition to the conserved disulfide bond within the domain. Hence, the increased sequence and loop structure of VHH expands the area of antibody binding to antigens and the diversity of antibodies while increasing the stability of its structure, resulting in VHH being able to withstand high temperatures and harsh extreme environments.

\subsection{Correlation between Anti-Id VHH and OTA}

In order to compare the OTA standard solutions with the VHH 2-24 solutions, standard inhibition curves were established by indirect competitive ELISA. The OTA standard curve (Figure 4a), which was extremely similar to the curve using the VHH as standard (Figure $4 \mathrm{~b}$ ), was S-shaped and suitable for the four-parameter logic equation. It was clear that the two standard curves had a linear range between $20 \%$ and $80 \%$ of the binding rate, indicating their obvious inhibition effect. To evaluate whether the anti-id VHH 2-24 could supersede OTA as a standard substance, we analyzed the correlation between the concentrations of VHH 2-24 and OTA. Based on the above two standard curves, we calculated the concentrations of OTA and $\mathrm{VHH} 2-24$ corresponding to the same binding rate between $20-80 \%$ and 
established a linear relationship. From Figure 5, the concentration of the OTA and VHH 2-24 standards material exhibited a good linear relationship $\left(y=1.0973 x-0.0639, R^{2}=0.9854\right)$. In brief, the results proved that VHH 2-24 could be used as an OTA surrogate calibrator for indirect competition ELISA.

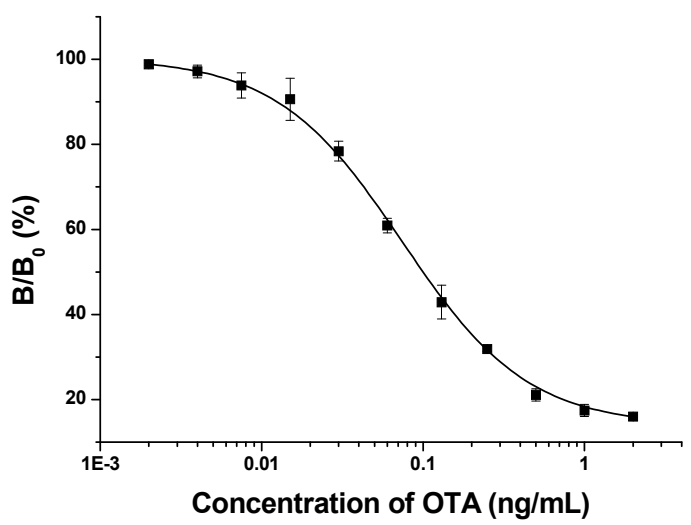

(a)

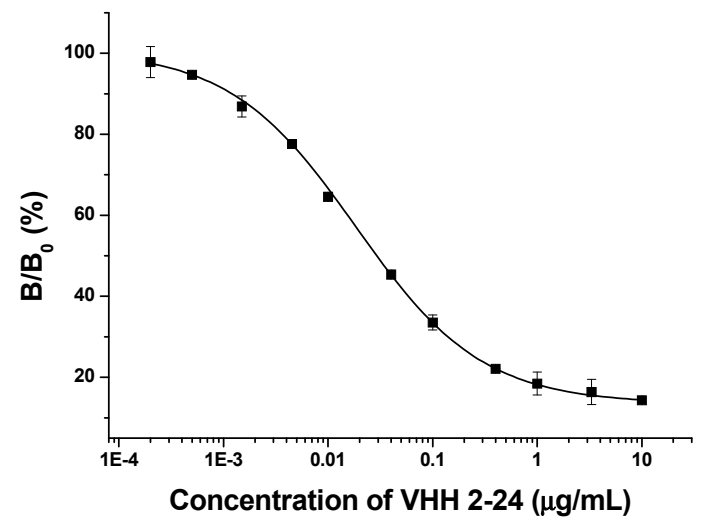

(b)

Figure 4. Standard curves of ELISAs using OTA (a) and VHH2-24 (b) as standards.

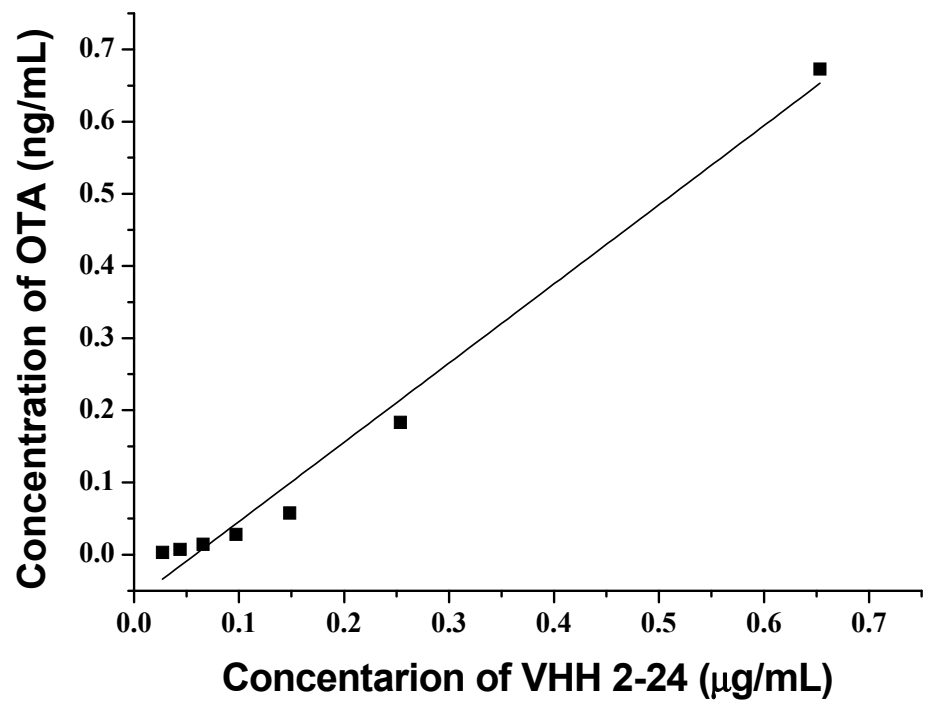

Figure 5. The linear relationship between the concentrations of OTA and VHH 2-24.

\subsection{Surrogate Standard Curve}

With a two-step calculation, OTA in actual samples was detected by the ELISA method based on a VHH 2-24 surrogate standard. The calculation method was as follows: First, the B/ $\mathrm{B}_{0}$ value of each well was obtained by the OD value of the samples measured by ELISA, and it was applied to the four-parameter logistic equation of the nanobody substitution to calculate the corresponding concentration of $\mathrm{VHH} 2-24$. The four-parameter logic equation is as follows:

$$
y=14.2118+\frac{85.7392}{1+\left(\frac{x}{0.0735}\right)^{1.2016}}, R^{2}=0.9988
$$

where $\mathrm{y}$ is the $\mathrm{B} / \mathrm{B}_{0}$ value and $x$ is the anti-id nanobody $\mathrm{VHH} 2-24$ concentration.

Then, the concentration of VHH 2-24 was converted into the corresponding OTA concentration by a quantitative conversion equation of $\mathrm{VHH}$ 2-24 and OTA concentration as follows:

$$
y=1.0973 x-0.0639, R^{2}=0.9854
$$


where $\mathrm{y}$ is the OTA concentration and $x$ is the VHH 2-24 concentration.

The two-step calculation displayed an excellent detection limit of $0.001 \mathrm{ng} / \mathrm{mL}\left(\mathrm{IC}_{10}\right)$ and a wide linear range for the OTA $\left(\mathrm{IC}_{20}-\mathrm{IC}_{80}\right)$ of $0.003-0.673 \mathrm{ng} / \mathrm{mL}$. Hence, OTA could be analyzed by using a toxin-free ELISA based on a VHH as a surrogate material.

\subsection{Assay Validation}

To validate the accuracy of the toxin-free ELISA based-VHH for sample analysis, we performed spike-and-recovery experiments. Corn, rice and wheat samples spiked with serial concentrations of OTA standard solution $(2 \mu \mathrm{g} / \mathrm{kg}, 10 \mu \mathrm{g} / \mathrm{kg}$ and $50 \mu \mathrm{g} / \mathrm{kg})$ were made on the pretreatment. The OTA content in the sample extract was detected by the newly established VHH based ELISA. As seen in Table 1, the results showed excellent correlations between the spiked and recovered concentrations. For intra-assay, an average recovery of $81.8 \%$ to $105.0 \%$ was achieved; meanwhile, the recovery for the inter-assay ranged from $88.0 \%$ to $93.0 \%$. Overall, the above assays indicate that the developed VHH 2-24 based-ELISA in this study was suitable for the determination of OTA in agricultural products.

Table 1. Recovery analysis of ELISA for OTA in agro-products.

\begin{tabular}{|c|c|c|c|}
\hline Sample Types & $\begin{array}{l}\text { Spike Level } \\
(\mu \mathrm{g} / \mathrm{kg})\end{array}$ & $\begin{array}{c}\text { Means } \pm \text { SD } \\
(\mu \mathrm{g} / \mathrm{kg})\end{array}$ & Recovery (\%) \\
\hline \multicolumn{4}{|c|}{ within assay $(n=3)^{\text {a }}$} \\
\hline \multirow{3}{*}{ Corn } & 50 & $41.2 \pm 5.1$ & 82.4 \\
\hline & 10 & $8.7 \pm 0.7$ & 87.0 \\
\hline & 2 & $1.8 \pm 0.2$ & 90.0 \\
\hline \multirow{3}{*}{ Rice } & 50 & $44.3 \pm 5.6$ & 88.6 \\
\hline & 10 & $10.2 \pm 0.4$ & 102.0 \\
\hline & 2 & $2.1 \pm 0.3$ & 105.0 \\
\hline \multirow{3}{*}{ Wheat } & 50 & $40.9 \pm 4.9$ & 81.8 \\
\hline & 10 & $9.7 \pm 1.0$ & 97.0 \\
\hline & 2 & $1.9 \pm 0.4$ & 95.0 \\
\hline \multicolumn{4}{|c|}{ between assay $(n=5)^{b}$} \\
\hline \multirow{3}{*}{ Corn } & 50 & $46.5 \pm 6.7$ & 93.0 \\
\hline & 10 & $8.8 \pm 0.7$ & 88.0 \\
\hline & 2 & $1.8 \pm 0.2$ & 90.0 \\
\hline
\end{tabular}

${ }^{a}$ Each assay was carried out in three replicates on the same day. ${ }^{b}$ The assays were carried out on five different days.

\subsection{Comparison between the ELISA Based on VHH and the HPLC Method}

Ten corn samples naturally contaminated with OTA were selected and the levels of OTA were determined by the newly developed ELISA and HPLC methods. Linear regression analysis was performed on the OTA concentrations measured by the two methods. As shown in Figure 6, the results of the two methods showed a good linear relationship $\left(y=1.0383 x-0.3787, R^{2}=0.994\right)$, which further proved that the detection of OTA in the sample by the toxin-free ELISA was accurate and reliable. 


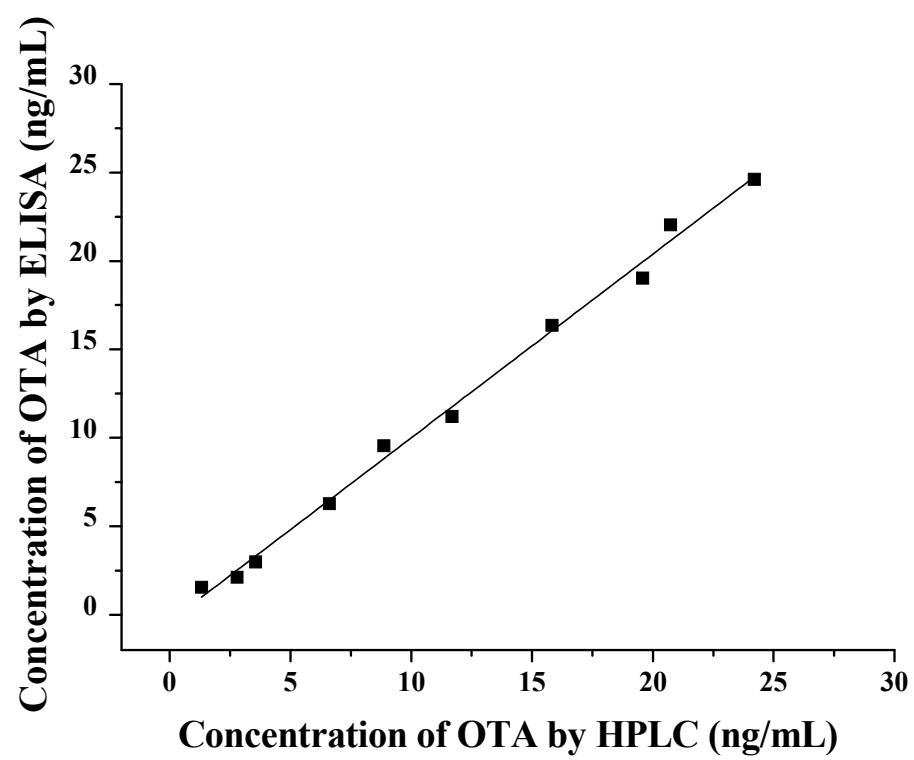

Figure 6. Correlation between the results of HPLC and ELISAs for OTA in contaminated corn samples.

\section{Conclusions}

In this study, we developed a toxin-free, sensitive and selective ELISA for the analysis of OTA based on a VHH surrogate standard. We also demonstrated the particular benefit of the proposed immunoassay, that is, the method can effectively prevent the health risk to the operator caused by OTA during the testing process. By immunizing alpaca with the anti-OTA $\mathrm{mAb} 1 \mathrm{H} 2$, an anti-id nanobody VHH 2-24 for OTA was successfully obtained. As we have proved, VHH 2-24 showed fine specificity and improved thermal stability. What is more, this study analyzed the correlation between the anti-id VHH antibody and OTA and showed good linearity, with an R2 value of 0.9854 . The accuracy of the newly developed method for OTA detection in spiked samples was verified, and the test results also revealed good recovery ranging from $81.8 \%$ to $105.0 \%$. Comparing the results of the OTA corn sample with the reference HPLC method, we observed a good correlation $\left(y=0.81 x+9.82, R^{2}=0.9922\right)$. In addition, the European Union has set strict maximum limits for OTA in food and feed, such as $10 \mu \mathrm{g} / \mathrm{kg}$ for instant coffee, $2 \mu \mathrm{g} / \mathrm{kg}$ for wine and $5 \mu \mathrm{g} / \mathrm{kg}$ for wheat. In conclusion, the above results indicate that the toxin-free ELISA established here is feasible for detecting OTA and it fulfills the requirements of the current legislation concerning the detection of OTA contamination in food and feed. Anti-id VHH has great potential in the development of immunoassay replacement reagents.

\section{Materials and Methods}

\subsection{Materials and Reagents}

All inorganic chemicals and organic solvents were of reagent grade unless stated otherwise. Anti-ochratoxin A monoclonal antibody (mAb) 1H2 [19], anti-aflatoxin B1 mAb 1C11 [40], anti-zearalenone $\mathrm{mAb} 2 \mathrm{D} 3$ [41] and anti-deoxynivalenol mAb 1D5 were produced in our laboratory. Nanobody VHH 2-24 was obtained and purified by following our previous instructions. Ochratoxin A standard, bovine serum albumin (BSA), polyethylene glycol 8000(PEG8000), Freund's incomplete adjuvant, isopropyl $\beta$-D-1-thiogalactopyranosi-de (IPTG), 3,3',5,5'-tetramethylbenzidine (TMB) and goat anti-mouse monoclonal antibody conjugated to horseradish peroxidase (HRP) were procured from Sigma (St. Louis, MO, SA). The Costar 96-well EIA/RIA plate was purchased from Corning Incorporated (Corning, NY, USA). Tween 20 was obtained from the J\&K Scientific (Beijing, China). XTractor buffer for protein extraction and His60 Superflow Resin were purchased from Clontech Laboratories, Inc. Mountain View, CA, USA). 0.01 M phosphate-buffered saline (PBS, pH 7.4) was 
prepared by adding $8 \mathrm{~g}$ of NaCl, $2.9 \mathrm{~g}$ of $\mathrm{Na}_{2} \mathrm{HPO}_{4} \cdot 12 \mathrm{H}_{2} \mathrm{O}, 0.2 \mathrm{~g}$ of $\mathrm{KH}_{2} \mathrm{PO}_{4}$ and $0.2 \mathrm{~g}$ of $\mathrm{KCl}$ in $1000 \mathrm{~mL}$ deionized water.

\subsection{Safety}

Pure OTA standards were handled with care in the fume hood. All containers in contact with phage, OTA and bacterial cultures (centrifuge bottles, vials, glassware, tubes, etc.) were immersed in a $10 \%$ bleach solution for $2-3 \mathrm{~h}$ before processing and then autoclaved. All disposable items (centrifuge tubes and pipette tips) were autoclaved before they were discarded.

\subsection{Expression and Purification of Anti-Id Nanobody to OTA}

The pComb3X phagemid vectors encoding VHHs inhibited binding to the coating antigen and unique DNA sequences were extracted from ER2738 clones and transformed into the E. coli strain TOP10F' cells. For expression, a single colony of TOP10F' cell carrying nanobody expression plasmid was selected and incubated in $4 \mathrm{~mL}$ of SB overnight. Two $\mathrm{ml}$ of the overnight culture was added to a $500 \mathrm{~mL}$ cultural flask, which contained $200 \mathrm{~mL}$ of SB medium with ampicillin $(50 \mu \mathrm{g} / \mathrm{mL})$ and tetracycline $(20 \mu \mathrm{g} / \mathrm{mL})$, and this was shaken at $37^{\circ} \mathrm{C}$ at $250 \mathrm{rpm}$. When the OD600 value of the culture reached about 0.6 , IPTG was added into the culture with a final concentration of $1 \mathrm{mM}$ and continuously shaken overnight at $250 \mathrm{rpm}$ at $37^{\circ} \mathrm{C}$.

The cell cultures were centrifuged at $8000 \times g$ for $10 \mathrm{~min}$ at $4{ }^{\circ} \mathrm{C}$ and periplasmic proteins were extracted by a XTractor buffer, then the VHH containing $6 \times$ His tag was purified with Ni-NTA metal affinity chromatography according to the manufacturer's instruction. The obtained soluble VHH was analyzed by SDS-PAGE for purity and size, and then concentrated by ultrafiltration tubes. Finally, the concentration of purified nanobody was determined by the Bradford method and stored at $-20^{\circ} \mathrm{C}$.

\subsection{Competitive ELISA Using OTA As Standard}

The 96-well ELISA plate was coated with $100 \mu \mathrm{L} /$ well of OTA-BSA $(0.2 \mu \mathrm{g} / \mathrm{mL})$ and incubated overnight at $4{ }^{\circ} \mathrm{C}$. The next day, the ELISA plate was washed three times with PBST (PBS with $0.05 \%$ Tween 20, v/v), and then blocked with $300 \mu \mathrm{L} /$ well of $3 \%$ skimmed milk in PBST for $1 \mathrm{~h}$ at $37^{\circ} \mathrm{C}$. After washing the plate three times again, $50 \mu \mathrm{L}$ of each serial concentration of OTA standard diluted with $10 \%$ methanol/PBS $(v / v)$ was mixed with an equal volume of monoclonal antibody $1 \mathrm{H} 2$ in PBS, and the mixture was added to each well of the microplate. After incubation for $1 \mathrm{~h}$ at $37^{\circ} \mathrm{C}$ and washing for three cycles with PBST, $100 \mu \mathrm{L}$ of goat anti-mouse antibody conjugated with HRP was added to each well followed by $1 \mathrm{~h}$ incubation at $37^{\circ} \mathrm{C}$. The color was developed by adding $100 \mu \mathrm{L}$ peroxidase substrate $(25 \mathrm{~mL}$ of $0.1 \mathrm{M}$ citrate acetate buffer [pH 5.5], $0.4 \mathrm{~mL}$ of $6 \mathrm{mg} / \mathrm{mL}$ TMB in dimethyl sulfoxide (DMSO), and $0.1 \mathrm{~mL}$ of $1 \% \mathrm{H}_{2} \mathrm{O}_{2}$ ). The plate was incubated for $15 \mathrm{~min}$ at $37^{\circ} \mathrm{C}$ until enzyme reactivity was terminated by adding $50 \mu \mathrm{L}$ of $2 \mathrm{M} \mathrm{H}_{2} \mathrm{SO}_{4}$. The absorbance was measured by a microplate reader (Molecular Devices, State of California, USA) at $450 \mathrm{~nm}$.

\subsection{Competitive ELISA Based on an Anti-Id VHH as Surrogate Standard}

In addition to using continuous concentrations of nanobody in place of free OTA, we established the same assay as competitive ELISA using OTA as a competitor.

\subsection{Sample Preparation}

Samples of rice, corn, and wheat purchased from the local supermarket were finely ground using a grinder and stored in the freezer at $-20^{\circ} \mathrm{C}$ before use. Five grams of each milled sample was weighed separately and extracted using $80 \%$ methanol in ultrapure water $(v / v)$. The mixture was shaken at $250 \mathrm{rpm}$ at room temperature for $30 \mathrm{~min}$, and then centrifuged at $5000 \mathrm{~g}$ for $30 \mathrm{~min}$; the filtered supernatant was diluted four times with $4 \%$ BSA/PBS $(w / v)$ and used for ELISA analysis after dilution. 


\subsection{HPLC-ELISA-Based Validation}

To assess the accuracy of the newly established indirect competitive ELISA method based on VHH as surrogate standard, the ten randomly selected corn samples naturally contaminated by OTA were analyzed by ELISA and compared with the results of the HPLC method. OTA analysis in the sample extract was performed on a Shiseido C18 analytical column (particle size $3 \mu \mathrm{m} ; 150 \times 4.6$ ). The excitation and emission wavelengths of the fluorescence detector were set to $333 \mathrm{~nm}$ and $470 \mathrm{~nm}$, respectively. The mobile phase consisted of a $45 \%$ methanol/water solution at a flow rate of $1 \mathrm{~mL} / \mathrm{min}$. The sample injection volume was $10 \mu \mathrm{L}$ and the column temperature was $30^{\circ} \mathrm{C}$.

Author Contributions: P.L. and Q.Z. contributed to the conception and design of the work; nanobody expression and purification, stability and specificity determination, method establishment and validation, data analysis and manuscript writing were completed by C.Z.; Q.Z., X.T. and W.Z. participated in the revision of the manuscript, and the final version of the manuscript was decided by Q.Z.

Funding: The research is supported by the Natural Science Foundation of China (2017YFC1200903) and the Major Project of Hubei Provincial Technical Innovation (2018ABA081).

Conflicts of Interest: The authors declare no competing financial interest.

\section{References}

1. Monteolzv, M.R.F.; Gorge, J.L.; Mayor, F. Ochratoxin A-A Toxic Metabolite produced by Aspergillus ochraceus Wilh. Nature 1965, 205, 1112-1113.

2. Varga, J.; Kevei, E.; Rinyu, E.; Teren, J.; Kozakiewicz, Z. Ochratoxin production by Aspergillus species. Appl. Environ. Microbiol. 1996, 62, 4461-4464. [PubMed]

3. Fazekas, B.; Tar, A.K.; Zomborszky-Kovacs, M. Ochratoxin a contamination of cereal grains and coffee in Hungary in the year 2001. Acta Vet. Hung. 2002, 50, 177-188. [CrossRef]

4. Barthelmebs, L.; Jonca, J.; Hayat, A.; Prieto-Simon, B.; Marty, J.-L. Enzyme-Linked Aptamer Assays (ELAAs), based on a competition format for a rapid and sensitive detection of Ochratoxin A in wine. Food Control 2011, 22, 737-743. [CrossRef]

5. Luhe, A.; Hildebrand, H.; Bach, U.; Dingermann, T.; Ahr, H.J. A new approach to studying ochratoxin A (OTA)-induced nephrotoxicity: Expression profiling in vivo and in vitro employing cDNA microarrays. Toxicol. Sci. 2003, 73, 315-328. [CrossRef]

6. Gross-Steinmeyer, K.; Weymann, J.; Hege, H.G.; Metzler, M. Metabolism and lack of DNA reactivity of the mycotoxin ochratoxin A in cultured rat and human primary hepatocytes. J. Agric. Food Chem. 2002, 50, 938-945. [CrossRef]

7. Costa, J.G.; Saraiva, N.; Guerreiro, P.S.; Louro, H.; Silva, M.J.; Miranda, J.P.; Castro, M.; Batinic-Haberle, I.; Fernandes, A.S.; Oliveira, N.G. Ochratoxin A-induced cytotoxicity, genotoxicity and reactive oxygen species in kidney cells: An integrative approach of complementary endpoints. Food Chem. Toxicol. 2016, 87, 65-76. [CrossRef] [PubMed]

8. Da Rocha, M.E.B.; Freire, F.D.O.; Maia, F.B.F.; Guedes, M.I.F.; Rondina, D. Mycotoxins and their effects on human and animal health. Food Control 2014, 36, 159-165. [CrossRef]

9. Murillo-Arbizu, M.T.; Amezqueta, S.; Gonzalez-Penas, E.; de Cerain, A.L. Occurrence of Ochratoxin A in Southern Spanish Generous Wines under the Denomination of Origin "Jerez-Xeres-Sherry and 'Manzanilla' Sanlucar de Barrameda". Toxins 2010, 2, 1054-1064. [CrossRef]

10. Chiotta, M.L.; Ponsone, M.L.; Sosa, D.M.; Combina, M.; Chulze, S.N. Biodiversity of Aspergillus section Nigri populations in Argentinian vineyards and ochratoxin A contamination. Food Microbiol. 2013, 36, 182-190. [CrossRef]

11. Vidal, A.; Sanchis, V.; Ramos, A.J.; Marin, S. Thermal stability and kinetics of degradation of deoxynivalenol, deoxynivalenol conjugates and ochratoxin A during baking of wheat bakery products. Food Chem. 2015, 178, 276-286. [CrossRef]

12. European Commission. Commission regulation (EC) No. 1881/2006 of 19 December 2006 setting maximum levels for certain contaminants in foodstuffs. J. Eur. Union 2006, 364, 5-24. 
13. Pittet, A.; Royer, D. Rapid, low cost thin-layer chromatographic screening method for the detection of ochratoxin A in green coffee at a control level of $10 \mathrm{mu} \mathrm{g} / \mathrm{kg}$. J. Agric. Food Chem. 2002, 50, 243-247. [CrossRef] [PubMed]

14. Lindenmeier, M.; Schieberle, P.; Rychlik, M. Quantification of ochratoxin A in foods by a stable isotope dilution assay using high-performance liquid chromatography-tandem mass spectrometry. J. Chromatogr. A 2004, 1023, 57-66. [CrossRef] [PubMed]

15. Li, T.; Jo, E.J.; Kim, M.G. A label-free fluorescence immunoassay system for the sensitive detection of the mycotoxin, ochratoxin A. Chem. Commun. 2012, 48, 2304-2306. [CrossRef] [PubMed]

16. Bougrini, M.; Baraket, A.; Jamshaid, T.; El Aissari, A.; Bausells, J.; Zabala, M.; El Bari, N.; Bouchikhi, B.; Jaffrezic-Renault, N.; Abdelhamid, E.; et al. Development of a novel capacitance electrochemical biosensor based on silicon nitride for ochratoxin A detection. Sens. Actuat. B-Chem. 2016, 234, 446-452. [CrossRef]

17. Wang, Y.Z.; Wei, D.P.; Yang, H.; Yang, Y.; Xing, W.W.; Li, Y.; Deng, A.P. Development of a highly sensitive and specific monoclonal antibody-based enzyme-linked immunosorbent assay (ELISA) for detection of Sudan I in food samples. Talanta 2009, 77, 1783-1789. [CrossRef]

18. Hu, W.; Li, X.; He, G.; Zhang, Z.; Zheng, X.; Li, P.; Li, C.M. Sensitive competitive immunoassay of multiple mycotoxins with non-fouling antigen microarray. Biosens. Bioelectron. 2013, 50, 338-344. [CrossRef] [PubMed]

19. Li, X.; Li, P.W.; Zhang, Q.; Zhang, Z.W.; Li, R.; Zhang, W.; Ding, X.X.; Chen, X.M.; Tang, X.Q. A Sensitive Immunoaffinity Column-Linked Indirect Competitive ELISA for Ochratoxin A in Cereal and Oil Products Based on a New Monoclonal Antibody. Food Anal. Methods 2013, 6, 1433-1440. [CrossRef]

20. Wang, Y.; Wang, H.; Li, P.; Zhang, Q.; Kim, H.J.; Gee, S.J.; Hammock, B.D. Phage-Displayed Peptide That Mimics Aflatoxins and Its Application in Immunoassay. J. Agric. Food Chem. 2013, 61, 2426-2433. [CrossRef]

21. Wang, Y.; Li, P.; Majkova, Z.; Bever, C.R.S.; Kim, H.J.; Zhang, Q.; Dechant, J.E.; Gee, S.J.; Hammock, B.D. Isolation of Alpaca Anti-ldiotypic Heavy-Chain Single-Domain Antibody for the Aflatoxin Immunoassay. Anal. Chem. 2013, 85, 8298-8303. [CrossRef] [PubMed]

22. Qiu, Y.-L.; He, Q.-H.; Xu, Y.; Bhunia, A.K.; Tu, Z.; Chen, B.; Liu, Y.-Y. Deoxynivalenol-mimic nanobody isolated from a naive phage display nanobody library and its application in immunoassay. Anal. Chim. Acta 2015, 887, 201-208. [CrossRef] [PubMed]

23. Ji, Y.; He, Q.; Xu, Y.; Tu, Z.; Yang, H.; Qiu, Y.; Wang, X.; Liu, Y. Phage displayed anti-idiotypic nanobody mediated immuno-PCR for sensitive and environmentally friendly detection of mycotoxin ochratoxin A. Anal. Methods 2016, 8, 7824-7831. [CrossRef]

24. Shu, M.; Xu, Y.; Wang, D.; Liu, X.; Li, Y.; He, Q.; Tu, Z.; Qiu, Y.; Ji, Y.; Wang, X. Anti-idiotypic nanobody: A strategy for development of sensitive and green immunoassay for Fumonisin B-1. Talanta 2015, 143, 388-393. [CrossRef]

25. Tang, X.; Li, P.; Zhang, Q.; Zhang, Z.; Zhang, W.; Jiang, J. Time-Resolved Fluorescence Immunochromatographic Assay Developed Using Two Idiotypic Nanobodies for Rapid, Quantitative, and Simultaneous Detection of Aflatoxin and Zearalenone in Maize and Its Products. Anal. Chem. 2017, 89, 11520-11528. [CrossRef]

26. Xu, Y.; Xiong, L.; Li, Y.P.; Xiong, Y.H.; Tu, Z.; Fu, J.H.; Chen, B. Anti-idiotypic nanobody as citrinin mimotope from a naive alpaca heavy chain single domain antibody library. Anal. Bioanal. Chem. 2015, 407, 5333-5341. [CrossRef]

27. Jerne, N.K. Towards a network theory of the immune system. Ann. Immunol. (Paris) 1974, 125C, $373-389$.

28. Nisonoff, A.; Lamoyi, E. Implications of the presence of an internal image of the antigen in anti-idiotypic antibodies-Possible application to vaccine production. Clin. Immunol. immunopathol. 1981, 21, 397-406. [CrossRef]

29. Jerne, N.K. The generative grammar of the immune system. EMBO J. 1985, 2, 847-852. [CrossRef]

30. Diaz, Y.; Gonzalez, A.; Lopez, A.; Perez, R.; Vazquez, A.M.; Montero, E. Anti-ganglioside anti-idiotypic monoclonal antibody-based cancer vaccine induces apoptosis and antiangiogenic effect in a metastatic lung carcinoma. Cancer Immunol. Immun. 2009, 58, 1117-1128. [CrossRef]

31. Chang, D.K.; Kurella, V.B.; Biswas, S.; Avnir, Y.; Sui, J.H.; Wang, X.Q.; Sun, J.S.; Wang, Y.Y.; Panditrao, M.; Peterson, E.; et al. Humanized mouse G6 anti-idiotypic monoclonal antibody has therapeutic potential against IGHV1-69 germline gene-based B-CLL. Mabs-Austin. 2016, 8, 787-798. [CrossRef] 
32. Hanoux, V.; Wijkhuisen, A.; Alexandrenne, C.; Creminon, C.; Boquet, D.; Couraud, J.Y. Polyclonal anti-idiotypic antibodies which mimic an epitope of the human prion protein. Mol. Immunol. 2009, 46, 1076-1083. [CrossRef]

33. Dormeshkin, D.O.; Kuprienko, O.S.; Svirid, A.V.; Gilep, A.A.; Sviridov, O.V.; Usanov, S.A. Generation and characterization of biotinylated recombinant Fab antibody fragment against cortisol. Russ. J. Bioorg. Chem. 2016, 42, 22-28. [CrossRef]

34. Miao, X.N.; Li, A.D.; Chen, W.; Qi, H.D.; Qiu, Z.; Zhang, Y.B.; Zhang, J.; Wang, M. Optimization and modification of anti-rhTNF-alpha single chain variable fragment antibody: Effective in vitro affinity maturation and functional expression of chimeric Fab. Biomed. Pharmacother. 2013, 67, 437-444. [CrossRef]

35. Hamers-Casterman, C.T.S.G.; Atarhouch, T.; Muyldermans, S.; Robinson, G.; Hammers, C.; Songa, E.B.; Hammers, R. Naturally occurring antibodies devoid of light chains. Nature 1993, 363, 446-448. [CrossRef] [PubMed]

36. Greenberg, A.S.; Avila, D.; Hughes, M.; Hughes, A.; McKinney, E.C.; Flajnik, M.F. A new antigen receptor gene family that undergoes rearrangement and extensive somatic diversification in sharks. Nature 1995, 374, 168-173. [CrossRef] [PubMed]

37. Jerne, N.K.; Ko, G. Ablynx makes nanobodies from llama bodies. Chem. Biol. 2006, 13, 1243-1244.

38. He, T.; Wang, Y.; Li, P.; Zhang, Q.; Lei, J.; Zhang, Z.; Ding, X.; Zhou, H.; Zhang, W. Nanobody-Based Enzyme Immunoassay for Aflatoxin in Agro-Products with High Tolerance to Cosolvent Methanol. Anal. Chem. 2014, 86, 8873-8880. [CrossRef]

39. Wang, Y.; Li, P.; Zhang, Q.; Hu, X.; Zhang, W. A toxin-free enzyme-linked immunosorbent assay for the analysis of aflatoxins based on a VHH surrogate standard. Anal. Bioanal. Chem. 2016, 408, 6019-6026. [CrossRef]

40. Zhang, D.H.; Li, P.W.; Zhang, Q.; Zhang, W.; Huang, Y.L.; Ding, X.X.; Jiang, J. Production of ultrasensitive generic monoclonal antibodies against major aflatoxins using a modified two-step screening procedure. Anal. Chim. Acta 2009, 636, 63-69. [CrossRef]

41. Tang, X.Q.; Li, X.; Li, P.W.; Zhang, Q.; Li, R.; Zhang, W.; Ding, X.X.; Lei, J.W.; Zhang, Z.W. Development and Application of an Immunoaffinity Column Enzyme Immunoassay for Mycotoxin Zearalenone in Complicated Samples. PLoS ONE 2014, 9, 7. [CrossRef] [PubMed]

(C) 2019 by the authors. Licensee MDPI, Basel, Switzerland. This article is an open access article distributed under the terms and conditions of the Creative Commons Attribution (CC BY) license (http://creativecommons.org/licenses/by/4.0/). 